\author{
Magdalena DOBISZEWSKA ${ }^{1}$ \\ Justyna KUZIAK ${ }^{2}$ \\ Piotr WOYCIECHOWSKI ${ }^{3}$ \\ Maja KĘPNIAK ${ }^{4}$
}

\title{
GŁÓWNE ASPEKTY TRWAŁOŚCI BETONU MODYFIKOWANEGO ODPADOWYM PYEEM BAZALTOWYM Z ODPYLANIA KRUSZYW W WYTWÓRNI MMA
}

\begin{abstract}
Przygotowanie kruszywa do mieszanek mineralno-asfaltowych powoduje powstawanie odpadu w postaci pyłu mineralnego w ilości ok. 5\% masy kruszywa. Właściwości pyłu zależą od kruszywa użytego do produkcji MMA. Problem utylizacji tego odpadu został częściowo rozwiązany poprzez wykorzystanie niewielkiej jego części, jako wypełniacza w MMA. Jednak duża ilość odpadu składowana jest na wysypiskach, bądź też używana jest w rekultywacji terenu. Opublikowane wyniki badań wskazują, że odpad ten może stanowić cenny składnik betonów cementowych. Może on być stosowany jako efektywny zamiennik części kruszywa drobnego. Rezultatem takiej modyfikacji jest doszczelnienie struktury betonu, co prowadzi do zwiększenia jego trwałości. Rezultaty badań $[4,5]$ wskazują, że modyfikacja betonu odpadowym pyłem bazaltowym korzystnie wpływa na wytrzymałość betonu, a cechy technologiczne mieszanki betonowej nie ulegają istotnemu pogorszeniu. W artykule przedstawione zostaną wyniki badań nad głównymi aspektami trwałości betonu modyfikowanego odpadowym pyłem bazaltowym. Zbadany zostanie wpływ takiej modyfikacji na wytrzymałość, mrozoodporność, przebieg karbonatyzacji i dyfuzję jonów chlorkowych. Rezultaty badań wskazują, że zastosowanie pyłu bazaltowego, jako częściowego zamiennika kruszywa drobnego w ilości do $20 \%$, wpływa na zwiększenie trwałości betonu.
\end{abstract}

Słowa kluczowe: pył odpadowy, trwałość, mrozoodporność, karbonatyzacja, dufuzja jonów chlorkowych, zagospodarowanie odpadów

\footnotetext{
${ }^{1}$ Autor do korespondencji/corresponding author: Magdalena Dobiszewska, Uniwersytet Technologiczno-Przyrodniczy w Bydgoszczy, Al. prof. S. Kaliskiego 7, 85-796 Bydgoszcz, +48523408389, magdalena.dobiszewska@utp.edu.pl

2 Justyna Kuziak, Politechnika Warszawska, Al. Armii Ludowej 16, 00-637 Warszawa, +48222346480, j.kuziak@il.pw.edu.pl

${ }^{3}$ Piotr Woyciechowski, Politechnika Warszawska, Al. Armii Ludowej 16, 00-637 Warszawa, +48222346483, p.woyciechowski@il.pw.edu.pl

${ }^{4}$ Maja Kępniak, Politechnika Warszawska, Al. Armii Ludowej 16, 00-637 Warszawa, +48222346228, m.kepniak@il.pw.edu.pl
} 


\section{Wprowadzenie}

Piasek naturalny powszechnie stosowany jest w produkcji betonu, jako kruszywo drobne. W wielu krajach obserwuje się obecnie znaczny niedobór odpowiedniej jakości piasku naturalnego, który może być stosowany do produkcji betonu [1]. W tej sytuacji poszukuje się innych materiałów, które stanowić mogą częściowy zamiennik piasku. Wykorzystanie różnego rodzaju odpadów przemysłowych w produkcji betonu, nie tylko redukuje zużycie surowców naturalnych, ale pozwala także na zagospodarowanie odpadów. Granulowany żużel wielkopiecowy, popiół lotny, czy też pył krzemionkowy, stosowane powszechnie jako dodatki mineralne do cementu, mogą być również wykorzystane w betonie, jako częściowy zamiennik piasku [1]. Częściowym substytutem kruszywa drobnego może być również mączka marmurowa [2], zmielony pumeks bazaltowy, czy też zmielone odpady ceramiczne [3].

$\mathrm{W}$ pracy przedstawia się wyniki badań betonu z dodatkiem pyłu będącego odpadem z produkcji mieszanki mineralno-asfaltowej, który stanowi częściowy zamiennik piasku. Przeprowadzone dotychczas badania $[4,5]$ wskazują na korzystny wpływ tego dodatku na niektóre właściwości betonu zwykłego.

\section{Charakterystyka odpadowego pyłu mineralnego}

Zastosowany do badań pył mineralny jest odpadem powstającym w procesie produkcji mieszanki z kruszywa stosowanego do produkcji mas mineralnoasfaltowych. W linii technologicznej produkcji MMA, kruszywa podawane są do suszarki, w której przebiega proces suszenia w temperaturze ok. $200^{\circ} \mathrm{C}$. Spaliny opuszczają suszarkę porywając pył kamienny z kruszywa i wyciągane są przez wentylator wyciągowy. W separatorze wytrącane zostają grubsze frakcje pyłów kamiennych (tzw. zgrubne), a frakcje drobne zatrzymują się w filtrze tkaninowym otaczarki. Te ostatnie gromadzone są w specjalnym zbiorniku i stanowią odpad produkcyjny. Odpad ten najczęściej jest wykorzystywany do budowy izolacyjnych warstw pośrednich na wysypiskach odpadów komunalnych, np. jako warstwa sanitarna, a także jako materiał do rekultywacji terenów wokół żwirowni. W badaniach zastosowano pyły mineralne z kruszyw bazaltowych (skład tlenkowy i uziarnienie - tab. 1, rys. 1). Powierzchnia właściwa pyłów wyznaczona aparatem Blaine`a wynosi $3500 \mathrm{~cm}^{2} / \mathrm{g}$ a gęstość $2,99 \mathrm{~g} / \mathrm{cm}^{3}$.

Uziarnienie pyłów mineralnych, pochodzących z filtrów suszarek kruszywa w wytwórniach MMA, wykazuje zróżnicowanie spowodowane nie tylko rodzajem wkładu surowcowego, ale również porą roku, w której zostały zgromadzone. W okresie zimowym, w porównaniu do okresu letniego, kruszywo przechowywane na hałdach ma większą wilgotność oraz niższą temperaturę. Im większa wilgotność kruszywa, tym większe cząstki zanieczyszczeń przylegają do jego powierzchni, co spowodowane jest większą adhezją wilgotniejszych cząstek. 
Dodatkowo $\mathrm{z}$ uwagi na temperaturę oraz wilgotność dostarczonego surowca, konieczne są modyfikacje parametrów procesu suszenia i odpylania: czasu trwania, temperatury oraz siły nadmuchu suszarki. Modyfikacje te oraz wyjściowy skład granulometryczny zanieczyszczenia kruszywa, powodują, że pył gromadzony w filtrach wykazuje znaczącą zmienność w cyklu rocznym. Ze wstępnych analiz dokonanych w wytwórniach MMA wynika, że w okresie zimowym w porównaniu do okresu letniego odpad charakteryzuje się większym udziałem grubszych frakcji, co potencjalnie będzie miało znaczący wpływ na cechy betonu cementowego modyfikowanego tym pyłem. Pył użyty w przedstawionych badaniach pochodził z produkcji w okresie letnim.

Tabela 1. Skład chemiczny pyłu bazaltowego PB i cementu portlandzkiego CEM I

Table 1. Chemical composition of powder basalt PB and Portland cement CEM I

\begin{tabular}{|l|c|c|c|c|c|c|c|c|c|c|}
\hline \multirow{2}{*}{ Mat. } & $\mathrm{SiO}_{2}$ & $\mathrm{Al}_{2} \mathrm{O}_{3}$ & $\mathrm{Fe}_{2} \mathrm{O}_{3}$ & $\mathrm{CaO}$ & $\mathrm{MgO}$ & $\mathrm{SO}_{3}$ & $\mathrm{~K}_{2} \mathrm{O}$ & $\mathrm{Na}_{2} \mathrm{O}$ & $\mathrm{Cl}^{-}$ & $\mathrm{LOI}^{-1}$ \\
\cline { 2 - 11 } \\
\hline $\boldsymbol{P B}$ & 38,16 & 12,68 & 15,88 & 15,16 & 7,66 & 0,20 & 0,83 & 2,91 & 0,068 & 4,16 \\
\hline $\mathrm{CEM}$ & 19,67 & 4,83 & 3,20 & 64,50 & 1,39 & 2,34 & 0,54 & 0,19 & 0,075 & 2,89 \\
\hline
\end{tabular}

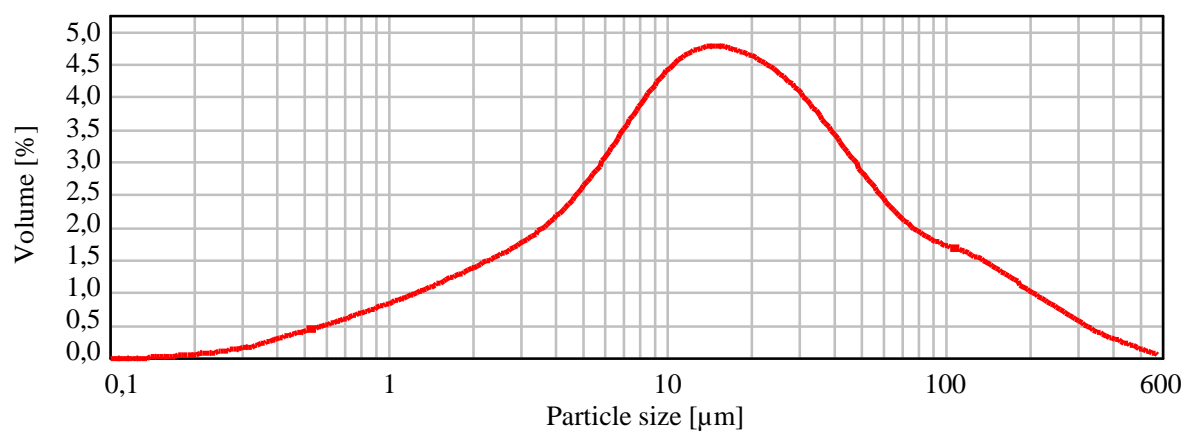

Rys. 1. Krzywa uziarnienia pyłu bazaltowego z produkcji w okresie letnim

Fig. 1. Grain curve distribution of basalt powder produced in summer period

Istniejące polskie i europejskie normy nie definiują zestawu badań koniecznych do wykonania w przypadku pyłów mineralnych stosowanych jako dodatek typu I-go do betonu. Dlatego na wstępnym etapie badań zasadne wydaje się badanie według norm odnoszących się do dodatków typu II, takich jak np. popiół lotny. W odniesieniu do tych dodatków, warunek wskaźnika aktywności zostaje spełniony głównie dlatego, że w jego składzie występuje aktywna krzemionka, która wchodzi w reakcję pucolanową [6]. Pyły odpadowe nie zawierają znaczących ilości takich substancji. Wstępne badania różnych pyłów wskazują jednak, że aktywność pucolanową wykazują niektóre pyły o szczególnie drobnym uziarnieniu. Wynika to z faktu, że odpadowy pył mineralny o drobnej granulacji skutkuje uszczelnieniem mikrostruktury, co ma bezpośredni wpływ na 
wynik badania aktywności pucolanowej. W podjętych badaniach przyjęto stosowanie pyłów, jako zamiennika części drobnego kruszywa a nie części spoiwa.

\section{Istota i zakres badań}

Celem przeprowadzonych badań było ustalenie wpływu dodatku odpadowego pyłu bazaltowego na niektóre właściwości betonu napowietrzonego, ze zwróceniem szczególnej uwagi na jego trwałość. Istota badań polegała na tym, że do mieszanki kruszywowej dodawano pył w taki sposób, że częściowo zastępował on piasek. Przeprowadzone doświadczenia obejmowały badanie wytrzymałości na ściskanie po 28 dniach i mrozoodporności betonu z pyłem odpadowym oraz analizę wpływu pyłów na przebieg karbonatyzacji i dyfuzję jonów chlorkowych. Wszystkie badania przeprowadzono dla betonu referencyjnego B0 oraz betonów B1 i B2 $\mathrm{z}$ dodatkiem pyłu odpadowego $\mathrm{w}$ ilości odpowiednio 10 i $20 \%$ masy piasku.

\section{Materiały i metody badań}

Wszystkie badane betony wykonano na bazie cementu portlandzkiego CEM I 42,5R (właściwości - tab.1) z piaskiem kwarcowym oraz kruszywem żwirowym z Kopalni Kruszyw Ostrowite (pomorskie). Zaprojektowano beton o stosunku w/c równym 0,4 z domieszką upłynniającą i napowietrzającą (tab.2).

Tabela 2. Skład mieszanek betonowych

Table 2. Concrete mixture proportion

\begin{tabular}{|c|c|c|c|c|c|c|c|c|}
\hline \multirow{2}{*}{ Beton } & Cement & piasek & $\begin{array}{c}\text { kruszywo } \\
2 / 8 \\
\end{array}$ & $\begin{array}{c}\text { kruszywo } \\
8 / 16 \\
\end{array}$ & woda & $\begin{array}{c}\text { pyt } \\
\text { bazaltowy }\end{array}$ & $S P$ & $\begin{array}{c}\text { dom. } \\
\text { napow. }\end{array}$ \\
\hline & \multicolumn{8}{|c|}{$\left[\mathrm{kg} / \mathrm{m}^{3}\right]$} \\
\hline BO & \multirow{3}{*}{351} & 586 & \multirow{3}{*}{547} & \multirow{3}{*}{820} & \multirow{3}{*}{141} & 0 & 2,2 & \multirow{3}{*}{2,1} \\
\hline$B 1$ & & 527 & & & & 59 & 3,5 & \\
\hline B2 & & 469 & & & & 117 & 3,5 & \\
\hline
\end{tabular}

Przeprowadzono następujące badania betonu: wytrzymałość na ściskanie (wg PN-EN 12390-3), mrozoodporność F50 i F150 (wg PN-B-06250) po 28 dniach na próbkach $100 \times 100 \times 100 \mathrm{~mm}$, odporność na karbonatyzację po 42 dniach (wg projektu EN 12390-12 - 4\% $\mathrm{CO}_{2}, 60 \% \mathrm{RH}, 20^{\circ} \mathrm{C}$, fenoloftaleina i tymoloftaleina [7]) oraz dyfuzja jonów chlorkowych (wg zasady podanej w PN-EN13396 z użyciem prawa Ficka do wyznaczenia współczynnika dyfuzji [8]).

\section{Wyniki badania właściwości uzyskanych betonów}

Wyniki wytrzymałości na ściskanie betonu w funkcji dodatku pyłu odpadowego (tab. 3) wskazują na korzystny wpływ pyłu na wytrzymałość betonu. 
Tabela 3. Wytrzymałość na ściskanie w funkcji zawartości pyłu bazaltowego

Table 3. Relationship between compressive strength and basalt powder content

\begin{tabular}{|c|c|c|c|}
\hline Beton & B0 & B1 & B2 \\
\hline $\begin{array}{c}\text { Wytrzymatość na ściskanie } \\
{[\mathbf{M P a}]}\end{array}$ & 72,71 & 80,64 & 78,82 \\
\hline
\end{tabular}

Dodatek pyłu, jako zamiennika piasku w ilości 10 i $20 \%$ spowodował wzrost średniej wytrzymałości betonu na ściskanie, odpowiednio o ok. 11 i $8 \%$.

Pył odpadowy korzystnie wpływa również na odporność betonu na działanie mrozu (rys. 2). Po 50 cyklach zamrażania i odmrażania, wytrzymałość próbek betonu referencyjnego obniżyła się w stosunku do próbek przechowywanych w wodzie o $7,5 \%$. W przypadku betonu z dodatkiem pyłu w ilości $10 \%$ masy piasku, nastąpił przyrost wytrzymałości próbek poddanych działaniu mrozu o $2 \%$ w stosunku do tzw. „świadków”. Przy dodatku pyłu w ilości 20\% masy piasku, wytrzymałość próbek po zamrażaniu i rozmrażaniu była praktycznie taka sama, jak ,świadków”. Po 150 cyklach zamrażania i odmrażania wytrzymałość na ściskanie betonu bez dodatku pyłu bazaltowego zmniejszyła się znacznie, tj. o $24 \%$ w stosunku do takich samych próbek przechowywanych w wodzie. Natomiast $\mathrm{w}$ przypadku próbek z pyłem bazaltowym nadal obserwowano wysoką odporność betonu na działanie mrozu - brak spadku wytrzymałości betonu z 10\% zawartością pyłu i zaledwie 3\%-owy spadek wytrzymałości betonu z 20\% pyłu.

Wpływ dodatku pyłu na przebieg karbonatyzacji w okresie badania do 42 dni w 4\% stężeniu $\mathrm{CO}_{2}$ (tab. 4) nie jest szczególnie wyraźny. Badanie fenoloftaleiną nie wykazało różnic pomiędzy betonami. Jednak badanie tymoloftaleiną wskazuje, że 20\%-owy udział pyłu spowalnia postęp karbonatyzacji, o czym świadczy mniejszy zasięg frontu $\mathrm{pH}=10,6$. Jest to prawdopodobnie spowodowane uszczelnieniem struktury przez ziarna pyłu odpadowego.

a)

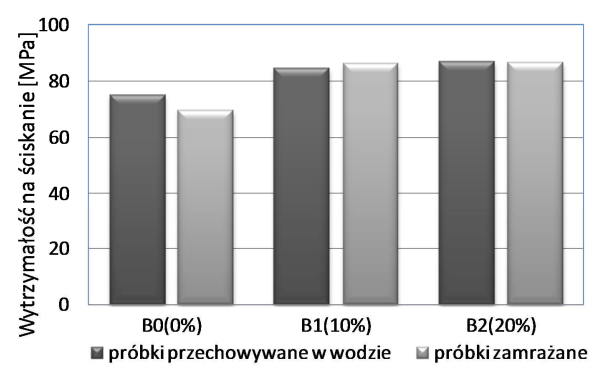

Zawartość pyłu bazaltowego b)

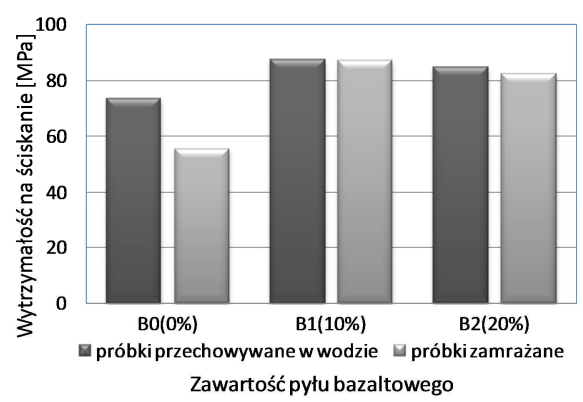

Rys. 2. Wytrzymałość na ściskanie próbek cyklicznie zamrażanych w funkcji zawartości pyłu bazaltowego: a) 50 cykli zamrażania i odmrażania, b) 150 cykli zamrażania i odmrażania

Fig. 2. Relationship between compressive strength of periodically frozen samples and basalt powder content: a) 50 freeze-thaw cycles, b) 150 freeze-thaw cycles 
Tabela 4. Głębokość karbonatyzacji po ekspozycji w $4 \%$ stężeniu $\mathrm{CO}_{2}$

Table 4. Depth of carbonation after exposure in $4 \%$ concentration of $\mathrm{CO}_{2}$

\begin{tabular}{|c|c|c|c|c|}
\hline \multirow[t]{2}{*}{ Czas ekspozycji } & \multirow{2}{*}{$\begin{array}{c}\text { Wskaźnik alkacymetryczny } \\
\text { i graniczne pH }\end{array}$} & \multicolumn{3}{|c|}{$\begin{array}{c}\text { Gtębokość karbonatyzacji beto- } \\
\text { nu, mm }\end{array}$} \\
\hline & & BO & $B 1$ & B2 \\
\hline \multirow[t]{2}{*}{$21 d n i$} & Fenoloftaleina $-p H=8,3$ & 0 & 0 & 0 \\
\hline & Tymoloftaleina $-\mathrm{pH}=10,6$ & 0 & 0 & 0 \\
\hline \multirow[t]{2}{*}{$42 d n i$} & Fenoloftaleina $-p H=8,3$ & 0 & 0 & 0 \\
\hline & Tymoloftaleina $-p H=10,6$ & 4,0 & 4,0 & 0 \\
\hline
\end{tabular}

Badanie współczynnika dyfuzji jonów chlorkowych w betonie (tab. 5) wykazało, że jest on bardzo zbliżony we wszystkich badanych betonach. Oznacza to, że w odniesieniu do dyfuzji jonów chlorkowych pyły nie spowodowały wystarczającego uszczelnienia betonu. Wniosek ten wymaga jednak uprawomocnienia poprzez wyznaczenie wyjściowej zawartości chlorków w betonie.

Tabela 5. Współczynniki dyfuzji jonów chlorkowych

Table 5. Diffusion coefficents of chloride ions

\begin{tabular}{|c|c|c|c|c|c|c|}
\hline \multirow{3}{*}{$\begin{array}{c}\text { Gtębokość } \\
\text { pobrania } \\
\text { próbki, mm }\end{array}$} & \multicolumn{6}{|c|}{ Oznaczenie sktadu } \\
\hline & \multicolumn{2}{|c|}{ BO } & \multicolumn{2}{|c|}{$B 1$} & \multicolumn{2}{|c|}{$B 2$} \\
\hline & $\begin{array}{c}\text { Stężenie Cl } \\
; \%\end{array}$ & $\begin{array}{c}\text { Wsp. } \\
\text { dyfuzji, } \mathrm{m}^{2} / \mathrm{s}\end{array}$ & $\begin{array}{c}\text { Stężenie Cl } \\
, \%\end{array}$ & $\begin{array}{c}\text { Wsp. } \\
\text { dyfuzji, } m^{2} / s\end{array}$ & $\begin{array}{c}\text { Stężenie Cl } \\
, \%\end{array}$ & $\begin{array}{c}\text { Wsp. } \\
\text { dyfuzji, } \mathrm{m}^{2} / \mathrm{s}\end{array}$ \\
\hline $1-2$ & 0,28 & \multirow{5}{*}{$\begin{array}{c}6,7 \times 10^{-12} \\
\left( \pm 0,8 \times 10^{-12}\right)\end{array}$} & 0,28 & \multirow{5}{*}{$\begin{array}{c}7,2 \times 10^{-12} \\
\left( \pm 1,3 \times 10^{-12}\right)\end{array}$} & 0,32 & \multirow{5}{*}{$\begin{array}{c}7,4 \times 10^{-12} \\
\left( \pm 1,2 \times 10^{-12}\right)\end{array}$} \\
\hline $3-4$ & 0,18 & & 0,19 & & 0,20 & \\
\hline $5-6$ & 0,11 & & 0,12 & & 0,13 & \\
\hline $7-8$ & 0,05 & & 0,05 & & 0,06 & \\
\hline $9-10$ & 0,02 & & 0,02 & & 0,03 & \\
\hline
\end{tabular}

Uziarnienie pyłu odpadowego zbliżone jest do uziarnienia cementu. Dodatek tego pyłu, jako zamiennika piasku, wpłynął na zmianę struktury badanego betonu, tj. zwiększył się udział mikroporów, kosztem porów o większych średnicach [5]. Doprowadziło to niewątpliwie do uszczelnienia struktury matrycy cementowej, co pozytywnie wpłynęło, zarówno na wytrzymałość betonu na ściskanie, jak i mrozoodporność.

\section{Podsumowanie}

Przeprowadzone badania miały na celu ocenę wpływu odpadowego pyłu bazaltowego z odpylania kruszyw na niektóre parametry betonu. Na podstawie rezultatów badań można wyciągnąć następujące wnioski:

1. Beton z dodatkiem pyłu odpadowego charakteryzuje się wyższą wytrzymałością i mrozoodpornością od betonu wykonanego bez pyłu.

2. Dodatek pyłu w ilości $20 \%$ spowolnił proces karbonatyzacji betonu. 
3. Pył bazaltowy ma niewielki wpływ na wartość współczynnika dyfuzji jonów chlorkowych.

Wzrost wytrzymałości na ściskanie betonu z dodatkiem odpadowego pyłu bazaltowego związany jest przede wszystkim z fizycznym oddziaływaniem tego odpadu, tj. uszczelnieniem struktury matrycy cementowej. Ma to również wpływ na większą odporność betonu wykonanego z dodatkiem pyłu bazaltowego na działanie mrozu, co jednocześnie ściśle wiąże się z jego trwałością. Przedstawione w literaturze wyniki badań zapraw cementowych wskazują, że pył bazaltowy może charakteryzować się właściwościami pucolanowymi [9-11]. Aktywność pucolanowa pyłów daje możliwość stosowania ich również, jako częściowego zamiennika cementu [9-11]. W takim przypadku obserwuje się niższą wczesną wytrzymałość cementu na ściskanie w porównaniu z zaprawą referencyjną [9]. W późniejszym natomiast okresie, wytrzymałość zaprawy z pyłem jest zbliżona lub nawet przewyższa wytrzymałość zaprawy referencyjnej, co wiąże się właśnie z pucolanowymi właściwościami pyłu bazaltowego [10, 11]. Przedstawione w pracy wyniki badań jednoznacznie wskazują na możliwość wykorzystania odpadowego pyłu bazaltowego powstającego przy produkcji MMA do produkcji betonu.

\section{Literatura}

[1] Rashad A.: Cementitious materials and agricultural wastes as natural fine aggregate replacement in conventional mortar and concrete, Journal of Building Engineering, 5, 2016, pp. 119-141.

[2] Alyamac K.E., Aydin A.B.: Concrete properties containing fine aggregate marble powder, KSCE Journal of Civil Engineering, 19(7), 2015, pp. 2208-2216.

[3] Binici H.: Effect of crushed ceramic and basaltic pumice as fine aggregates on concrete mortars properties, Construction and Building Materials, 21, 2007, 1191-1197.

[4] Dobiszewska M.: Beton z dodatkiem mineralnego pyłu odpadowego, Materiały Budowlane, 5, 2015, 63-64.

[5] Dobiszewska M., Franus W.: Wpływ dodatku mączki bazaltowej na niektóre właściwości betonu zwykłego, Wybrane zagadnienia konstrukcji i materiałów budowlnych oraz geotechniki, Wydawnictwa Uczelnianie Uniwersytetu TechnologicznoPrzyrodniczego w Bydgoszczy, Bydgoszcz 2015.

[6] Jackiewicz-Rek W., Kształtowanie mrozoodporności betonów wysokopopiołowych, Rozprawa doktorska, Politechnika Warszawska, 2010.

[7] Woyciechowski P., Model karbonatyzacji betonu, Prace naukowe. Budownictwo. z.57, Oficyna Wydawnicza Politechniki Warszawskiej, Warszawa 2013.

[8] Czarnecki L., Królikowski A., Kuziak J. i in. Ocena skuteczności działania migrujących inhibitorów korozji stali w betonie, Oficyna Wydawnicza Politechniki Warszawskiej, Warszawa 2008.

[9] Mucteba U., Kemalettin Y., Metin I.: The effect of mineral admixtures on mechanical properties, chloride ion permeability and impermeability of self-compacting concrete, Construction and Building Materials, 27, 2012, pp. 263-270. 
[10] Liu L., Zhang Y., Zhang W., Liu Z., Zhang L.: Investigating the influence of basalt as mineral admixture on hydration and microstructure formation mechanism of cement, Construction and Building Materials, 48, 2013, pp. 434-440.

[11] Saraya M. E. I.: Study physico-chemical properties of blended cements containing fixe amount of silica fume, blast furnace slag, basalt and limestone, a comparative study, Construction and Building Materials, 72, 2014, pp. 104-112.

\title{
MAJOR ASPECTS OF CONCRETE DURABILITY MODIFIED BY BASALT WASTE POWDER FROM AGGREGATE DEDUSTING IN ASPHALT BATCH MIX PLANT
}

\begin{abstract}
S u m m a r y
Asphalt mixture production results in formation of significant amount of by-product (ca. $5 \%$ of aggregate mass) in the form of mineral powder. Properties of this powder depend on the type of aggregate used in production. A problem of utilization of this by-product is solved partially by Asphalt Batch Mix Plant, which can use a small amount of the powder in MMA production. But huge amounts of this waste are collected on landfills or are used in land reclamation. Published research results, which concerns basalt waste powder, indicate that this by-product can be a valuable component of cement concrete. It can be used as an effective substitute of part of fine aggregate. Such a modification results in densifying of concrete matrix, which leads to improving of durability. Results published in the papers $[4,5]$ show that it is possible to increase compressive strength due to the concrete modification with basalt waste powder, while technological properties of mix are not worsened. The present study shows the effect of partial replacement of fine aggregate by basalt waste powder on major aspects of concrete durability. The influence of such a modification of concrete composition on frost resistance, carbonation and chloride ion diffusion was investigated, as well as the effect on compressive and flexural strength. Results of tests show that replacement of sand by waste basalt powder in amount of up to $20 \%$ improves concrete durability.
\end{abstract}

Keywords: dust waste, durability, freeze resistance, carbonation, ion chloride diffusion, waste management

Przestano do redakcji: 07.06.2016 $r$.

Przyjęto do druku: 30.06.2016 r.

DOI: $10.7862 / r b .2016 .13$ 